\title{
DESIGN E EDUCAÇÃO: UMA ESTRATÉGIA INTERDISCIPLINAR PARA A ESCRITA MANUAL CURSIVA NA ERA DOS NATIVOS DIGITAIS
}

\author{
Juliana Oliveira Guimarães \\ Universidade do Estado de Minas Gerais \\ Sérgio Antônio Silva, Dr. \\ Universidade do Estado de Minas Gerais \\ sergio.antonio74@hotmail.com
}

Resumo: A escrita foi uma das grandes invenções que revolucionou a história da humanidade, pois trouxe consigo uma nova possibilidade para a transmissão de conhecimento, descobertas e ideias. Atualmente, observase um afastamento entre o homem moderno e as letras manuais, optandose pela comunicação digital. Sendo assim, este artigo é um estudo teórico que se propôs a investigar de que maneira o Design pode contribuir no processo de ensino da escrita manual cursiva para os nativos digitais. Apresenta a importância do ensino dessa escrita e a perspectiva interdisciplinar do Design como estratégia para se trabalhar em conjunto com professores nas salas de aula.

Palavras-chave: Escrita, Design, interdisciplinaridade, nativos digitais.

\begin{abstract}
Writing was one of the greatest inventions that revolutionized the History of humankind, because it brought with itself a new possibility for transmission of knowledge, discoveries and ideas. Currently, there is a gap between modern man and manual letters, opting for digital communication. Therefore, this article is a theoretical study that aims to investigate how the design can help in the teaching of cursive handwriting to digital natives. It shows the importance of the teaching of handwriting and interdisciplinary perspective of design as a strategy to work together with teachers in classrooms.
\end{abstract}

Keywords: Handwriting, Design, interdisciplinary, digital natives. 


\section{INTRODUÇÃO}

De todas as invenções do homem até o presente momento, pode-se considerar a escrita como um dos grandes adventos que modificaram a História. A partir do momento em que o homem começa a escrever, ele cria uma nova possibilidade para armazenar seus conhecimentos, descobertas, invenções, história, cultura e transmitir tudo isso para as futuras gerações, algo que até então era feito somente por meio da fala e da memória.

Antes considerada uma habilidade de extrema importância na definição social das pessoas, atualmente, na Era Digital ou Era da Informação, nota-se que o computador e demais mídias digitais são ferramentas tecnológicas que têm afastado o homem dos tradicionais suportes e instrumentos para a escrita manual: a pena (a caneta, o lápis), o papel (o pergaminho, o papiro) e a tinta.

No ano de 2001, o designer de jogos, escritor e pesquisador Marc Prensky criou o termo "nativos digitais" para designar àquelas pessoas nascidas após a década de 1980, período em que se iniciou a Era Digital. Segundo Silvana Lemos (2009), entenda-se por nativos digitais jovens que fazem parte de uma geração imersa na tecnologia, que estão acostumados a receber informações de forma acelerada e paralela a outros processos. São os primeiros que aprendem de maneira não linear, por meio de hipertextos e vivem imersos em diferentes comunidades de aprendizagem.

Por conseguinte, frente ao cenário das inovações tecnológicas e das características específicas desse grupo de pessoas (nativos digitais), atualmente, temse colocado em discussão no ambiente escolar o uso da escrita manual e, em especial, da escrita manual cursiva, no cotidiano dos alunos da Era Digital.

O objetivo deste trabalho é investigar de que maneira o Design pode contribuir no processo de ensino da escrita manual cursiva para os nativos digitais. Trata-se de uma pesquisa bibliográfica, dividida em duas etapas. A primeira consistiu no levantamento de um referencial teórico, tendo como base publicações científicas e literaturas referentes ao tema em questão. A segunda etapa baseou-se na análise crítica dessas leituras, na seleção dos textos mais pertinentes à pesquisa e na interpretação dos dados e das informações levantados.

Ao longo do trabalho foi possível identificar a relevância do Design no contexto escolar no que diz respeito à sua natureza interdisciplinar, e como esta inserção tem funcionado em instituições no exterior. Além disso, foi explorado o conceito de Educação através do Design (EdaDe), desenvolvido pelo Prof. Dr. Antônio Martiniano Fontoura, possibilitando a busca por soluções que poderão auxiliar o processo de ensino e manutenção da escrita manual cursiva dos nativos digitais para que, ao longo dos anos letivos, consiga-se manter o interesse dos alunos em valorizar uma escrita pessoal e manual.

\section{DESENVOLVIMENTO}

Perante a influência das novas tecnologias e adicionando-se a importância da escrita da manual cursiva como expressão gráfica individual e cultural, conforme considera Priscila Farias (2001), elaborou-se a seguinte questão inserida na temática Design e Educação: como o Design pode contribuir com o aprendizado e o desenvolvimento da escrita manual cursiva dos nativos digitais? 
Para tanto, faz-se necessário compreender tal geração inserida na Era Digital, pois segundo Marcelo Veras et al. (2001), as gerações são produtos de fatos históricos que influenciam profundamente os valores e a visão de mundo de seus membros. Compreender o processo de evolução das gerações que compõe e que compuseram a sociedade é buscar compreender os fatores que as caracterizam, além de possibilitar a análise do contexto histórico em que as mesmas estão inseridas.

Entre 1984 e 1999 compreende-se o período de nascimento daqueles que compõe a Geração Y, marcada por filhos protegidos por uma sociedade preocupada basicamente com a segurança; crianças alegres e seguras, imersas num contexto em que as tecnologias mudam de forma contínua e vertiginosa na Era pós-moderna. Uma vez que conseguem obter a informação desejada por um "clique", utilizam cada vez menos os livros como fontes de pesquisa e aprendizado. Estão inseridos na chamada Era Digital ou Era da Informação.

Atualmente, uma nova geração surge no contexto da Era Digital, denominada por Veras et al. (2005) como sendo a Geração Z, composta essencialmente pelos nativos digitais, compreendendo as pessoas que nasceram entre meados dos anos 90 do século passado até a década presente. Segundo Lemos (2009), os nativos digitais vivem imersos em diferentes comunidades de aprendizagem e são os primeiros que aprendem de maneira não linear, absorvem melhor as informações e tomam decisões mais rapidamente; são multifacetada e processam informações em paralelo; uma geração que pensa graficamente, ao invés de textualmente (VERAS et al., 2011 apud PRENSKY, 2004).

\subsection{Os nativos digitais e a escrita manual cursiva}

Em se tratando dos processos de aquisição e manutenção da escrita manual cursiva, tem-se nos nativos digitais a busca por formas alternativas de comunicação interpessoal. Inseridos em um universo marcado pela hipertextualidade e mídias digitais diversas, essa geração tende a abandonar práticas antes consideradas fundamentais para a qualificação de um indivíduo enquanto trabalhador ou pertencente a uma determinada classe social, tal qual era a o ato de escrever à mão.

Em diversos países do mundo pode-se observar um processo de desvalorização da escrita manual cursiva fomentado pela Era Digital. Nos Estados Unidos, no ano de 2011, o Estado de Indiana, aboliu o ensino obrigatório da escrita cursiva em suas escolas, incentivando os professores a não dar prioridade ao ensino das letras escritas à mão e, sim, à digitação em teclados. Na Finlândia, a partir de setembro de 2015, as crianças que ingressaram no ensino fundamental foram as últimas a ter aulas de caligrafia no país; até setembro de 2016, as aulas de caligrafia deverão ser substituídas por aulas de computação.

No Brasil, a transição da escrita cursiva para os meios digitais (computadores, tablets e demais mídias) nas escolas públicas e até mesmo em uma parcela das escolas particulares, ainda é um processo distante mediante o cenário econômico e a cultura de muitas dessas escolas, porém não exclui o uso da tecnologia no cotidiano dos nativos digitais brasileiros.

Mediante os fatos apresentados, o questionamento que se faz é o seguinte: o que leva um povo a abolir o ensino da escrita manual cursiva? As justificativas apresentadas pelas autoridades educacionais são as mais variadas possíveis. Por exemplo, para os finlandeses a falta de legibilidade da letra dos alunos por parte dos 
professores e o tempo despendido para o ensino e aprendizagem da escrita cursiva são grandes problemas para suas escolas.

Nos EUA, os defensores da nova lei de Indiana acreditam que a base para tal medida está centrada na premissa de que as crianças, atualmente, pouco utilizam o papel e o lápis, pois a maior parte de suas atividades e trabalhos é realizada através de um computador, sendo assim, devem aprender a digitar com rapidez e facilidade.

O cenário brasileiro vivenciou situação semelhante, guardada devidas proporções, no século XIX mediante a chegada da máquina de escrever no país. Até então, o modelo de escrita ensinado era a caligrafia inclinada americana. Em Minas Gerais, por exemplo, a partir da Reforma da Instituição Primária, em 1906, passa-se a exigir o ensino de outro modelo de escrita caligráfica, a vertical ou redonda, indicada como sendo uma escrita adequada à vida moderna, por assemelhar-se à verticalidade das letras geradas pela máquina de escrever.

Trinta anos mais tarde, contudo, a máquina de escrever passou a não mais ser considerada como um paradigma para o ensino da escrita e, sim, como um problema para o desenvolvimento da "boa letra pessoal". Entre os educadores surgiu a ideia de que essa tecnologia estava fazendo com que os escolares perdessem o interesse em desenvolver uma a escrita pessoal. Sendo assim, começou dentro das escolas o debate sobre o mérito de se ensinar a "boa letra".

Atualmente, assim como no Brasil houve a tentativa de se aproximar a letra escrita manualmente àquela gerada pela máquina de escrever e o consequente desinteresse dos alunos em escrever à mão, percebe-se na iniciativa americana e finlandesa a aproximação com o digital e o abandono gradativo do contato dos nativos digitais com o lápis e o papel.

Fernanda Henriques; Laís Margadona; Marcela Gadotti (2014) acreditam que a escrita é um processo que envolve o corpo, pois tem-se o contato da mão e do lápis, o manuseio do mesmo, a influência da força e da condição motora na composição dos traços que originarão as letras. No meio digital, a composição dos textos dá-se por um processo meramente tátil, ou seja, o usuário não terá a mesma experiência proporcionada pelo processo "rústico".

Para Magda Soares (2011), a escrita representa um universo de significação de maior amplitude e não se limita a expressão gráfica, mas se constitui em instrumento de "aprendizagem para a vida social" no que se refere à intimidade da comunicação possibilitada nas relações interpessoais.

\footnotetext{
Saber escrever à mão é parte da noção que construímos, nos últimos séculos, de ser humano civilizado. Ser capaz de escrever de próprio punho e ser capaz de usar tecnologias antigas como a caneta ou o lápis continua sendo parte importante na definição de cidadão alfabetizado e letrado [...] Na França, por exemplo, uma carta de recomendação escrita à mão tem um valor simbólico muito maior que o mesmo texto digitado e apenas assinado. (CARVALHO, 2011 apud Morais, 2011).
}

Outro ponto relevante para a defesa da escrita é o aspecto do desenvolvimento cerebral das crianças. Neste sentido, Alyssa Kerley e Karin James (2013) consideram que: 
digitá-las [...] A formação de uma letra própria cursiva durante o aprendizado das crianças leva ao desenvolvimento de uma rede motora sensorial, conhecida por também ser ativada durante a percepção das letras na leitura [...] Esta constatação contribui para os estudos que sugerem que a formação de uma escrita própria é importante para a criação de um sistema de leitura no cérebro em desenvolvimento (KERLEY, JAMES, 2013, p. 1,13, tradução da autora).

Ainda a respeito da cognição e da prática da escrita manual cursiva Soares (1995) salienta:

\begin{abstract}
escrever engloba desde a habilidade de traduzir fonemas em grafemas, até habilidades cognitivas e metacognitivas; inclui habilidades motoras, ortografia, uso adequado da pontuação, a habilidade de selecionar informações relevantes sobre o tema do texto e de identificar os leitores pretendidos, a habilidade de fixar os objetivos do texto e de decidir como desenvolvê-lo, a habilidade de organizar as ideias no texto, de estabelecer relações entre elas, de expressá-las adequadamente (SOARES, 1995 p. 9).
\end{abstract}

Posto isto, acredita-se, portanto, que abolir o ensino da escrita das escolas prejudique o desenvolvimento das crianças na formação de uma letra pessoal e na compreensão e identificação de caracteres no ato da leitura, consequentemente, afetando a capacidade interpretativa e o aprendizado das palavras no que diz respeito à ortografia - entendo que o computador e as mídias digitais disponibilizam os chamados "corretores automáticos", por exemplo.

\title{
2.2 O Design e a escrita
}

No momento atual, tem-se uma infinidade de recursos tecnológicos sendo desenvolvidos e explorados em todas as áreas do saber humano, resultantes da Era da Informação. Com tantas ferramentas disponíveis, busca-se aplicações para as mesmas nos diversos estratos do conhecimento. No contexto educacional, não é diferente.

Considerando que as escolas do século XXI devem aprender a lidar com o universo em que seus alunos, os nativos digitais, estão inseridos, algumas já adotaram medidas que tentam importar para o ambiente educacional a tecnologia presente no cotidiano desses indivíduos. Embora nem todas as escolas possuam recursos financeiros para atualizar-se tecnologicamente e/ou uma política de incentivo a isso, fora das salas de aula seus alunos não deixam de estar inseridos na Era Digital.

Portanto, se uma mudança na concepção de ferramentas e recursos que podem ser agregados nas salas das escolas está acontecendo, faz-se necessário pensar nas consequências que podem recair sobre a metodologia de ensino atual, em destaque, sobre aquelas que envolvem o ensino e prática da escrita cursiva frente à absorção tecnológica dos nativos digitais.

Ao longo dos anos, adventos tecnológicos trouxeram consigo certa preocupação educativa no que concerne à influência desses novos recursos dentro do ambiente escolar e no aprendizado e comportamento dos alunos. Neste entendimento, Monica Fantin (2010, p. 91) acredita que "a educação e a formação devem desenvolver uma atenção precisa ao conjunto destas transformações, sobretudo pelo seu significado cultural e pelos comportamentos sociais que promovem".

Como, então, alvitrar caminhos, possíveis soluções e ideias em um debate complexo que envolve todo um processo metodológico e pedagógico? O que tem sido 
proposto por pesquisadores como solução para o aperfeiçoamento de metodologias no ambiente de ensino atual é a interdisplinaridade.

Por interdisplinaridade entende-se o intercâmbio de comunicação existente entre duas ou mais disciplinas que pode acontecer por meio da troca de informações relacionadas aos conceitos epistemológicos e por meio da organização do conhecimento e dos processos metodológicos e pedagógicos relativos ao ensino (FONTOURA, 2011).

Contudo, ao falar sobre interdisciplinaridade no ambiente acadêmico, pesquisadores registram certo descontentamento e preocupação por parte do corpo docente no que diz respeito ao valor individual das disciplinas escolares e às consequências que uma interação entre as mesmas poderia causar, sem a redução de conhecimentos científicos distintos a uma ótica apenas instrumental (OLIVEIRA; TEIXEIRA; MACIEL, 2006).

A esse respeito, Andréia Bonatto et al. (2012) propõe que através da interdisplinaridade, é possível abranger temáticas e conteúdos diversos, possibilitando a inserção de "recursos inovadores e dinâmicos".

A interdisciplinaridade não dilui as disciplinas, ao contrário, mantém sua individualidade. Mas integra as disciplinas a partir da compreensão das múltiplas causas ou fatores que intervêm sobre a realidade e trabalha todas as linguagens necessárias para a constituição de conhecimentos, comunicação e [...] significados (BONATTO et al., 2012, p. 3 apud BRASIL, 1999 , p. 89)

Nesta continuidade, percebe-se no Design a natureza interdisciplinar, uma vez que uma de suas características é o envolvimento com conhecimentos de domínios distintos. O acervo intelectual do designer é composto por disciplinas presentes nos diversos estratos do conhecimento, tais como antropologia, psicologia, semiótica, ergonomia, tipografia, engenharia, tecnologia, artes etc. Dessa forma, a interdisciplinaridade é um pré-requisito para esta atividade, pois além de comunicar consigo na criação e no desenvolvimento de projetos, há uma característica no designer que é de extrema relevância para o contexto dos nativos digitais: a habilidade de centrar seu trabalho nas necessidades de seus usuários (BROWN, 2010).

Solange Coutinho e Maria Tereza Lopes (2010) destacam que aproximar o campo do design ao da educação permite a construção de uma perspectiva centrada nos domínios e princípios de design que possam contribuir com as atividades educacionais, tornando-os participantes da construção do pensamento social.

A partir destas considerações, foi criado, em 2002, por Antônio Fontoura o princípio da EdaDe ou Educação através do Design em que acredita-se que atividades de design voltadas para o ambiente educacional, principalmente aquelas que estimulem o desenho e a construção (características presentes no processo de formação de uma escrita cursiva pessoal) são meios eficazes que permitem ensinar e aprender de forma ativa e interdisciplinar", desenvolvendo, dentre várias habilidades práticas, a comunicação escrita.

Por atividades de design, Renato Bordenousky Filho et al. (2005) explica que estas não se limitam a ação, pelo contrário, envolvem antes, a formação da consciência sobre o que vai ser feito. No projeto escolar, a partir destas práxis, os alunos não se limitam a mudar a forma da matéria que lhes é oferecida, pelo contrário, 
realizam nela a sua finalidade, estabelecem conexões entre a teoria e a prática, propiciando a abordagem interdisciplinar e a exploração do processo criativo.

Através destas atividades, Alice Pereira et al. (2003) afirma que é possível desenvolver nos alunos habilidades comuns aos designers, como a capacidade de análise, síntese e outras habilidades associadas às duas primeiras, como habilidades mentais - falar, discutir, observar, contextualizar etc.

Posto isto, três atividades de design baseadas no National Curriculum Britânico - aquele que define as matérias e áreas curriculares essenciais para o ensino primário e secundário -, são conceituadas na EdaDe. A primeira corresponde à Investigative, disassemble and evaluate activities, em outras palavras, são atividades que envolvem habilidades de "investigação, desmontagem, análise e avaliação de produtos e objetos", ou seja, a partir de um produto já existente, leva-se o educando a pensar por que um designer o desenhou como tal. A segunda é conhecida como Focused practical tasks, atividades de caráter prático que trabalham com situações em que os alunos desenvolvem habilidades específicas de construção, aprendendo através de uma técnica ou pela utilização de "ferramentas, equipamentos, máquina ou materiais". O terceiro tipo de atividade é denominada Design and Making Assignments, que incentiva o desenho e a "construção de coisas reais em termos de utilização de processos, aplicações de técnicas, uso de equipamentos e materiais".

Fontoura (2002) evidencia que, internacionalmente, tem sido demonstrado que essas atividades de design quando aplicadas ao ensino, enriquecem e "interferem positivamente nos processos de aprendizagem da criança". Ele cita a inclusão do "Design and Technology" como disciplina no Currículo Nacional Inglês e Galês; as disciplinas "Design \& Technology" e da "Art \& Crafts" no currículo escolar em Cingapura, o programa "Design for Thinking" da University of the Arts da Filadélfia, cujo objetivo é desenvolver pesquisas e tornar acessível e executável a educação através do design e da arte para os professores, alunos e a comunidade em geral.

O Brasil tem seu próprio modo de promover a educação de crianças e jovens - um sistema organizado, leis educacionais, parâmetros curriculares, etc. -; com certeza, modernos e atuais. Entretanto, no seu currículo oficial não constam matérias como Educação em Design, Design e Tecnologia ou Educação Tecnológica (BORDENOUSKY et al. 2005, p. 2).

Uma iniciativa merecedora de destaque foi a implantação do Programa de Iniciação Universitária em Design no Departamento de Artes da Pontifícia Universidade Católica do Rio de Janeiro (PUC-Rio).

\footnotetext{
O trabalho teve início em 1997 através de uma experiência piloto que tinha como objetivo levar noções de design, através do exercício de projeto, a uma turma da terceira série do primeiro ciclo do ensino fundamental, numa escola municipal do Rio de Janeiro (FONTOURA, 2002, p. 218).
}

Embora unir design e educação seja uma proposta relativamente recente para o ensino das escolas brasileiras, além do aspecto interdisciplinar do primeiro, como fora anteriormente abordado, destaca-se também os conhecimentos tipográficos desenvolvidos e pesquisados por designers ao longo dos anos de crescimento intelectual da profissão.

Segundo Adriana Batista; Fernanda Vianna; Luís Filipe Barbeiro (2011), considerando que o alfabeto é composto por grafemas maiúsculos e minúsculos, é 
importante que os professores tenham conhecimento com relação às diferenças estruturais de tais sinais gráficos, no que diz respeito tanto às letras originadas digitalmente quanto às produzidas pela caligrafia manual.

Em ambos os casos se tem segmentos de reta, linhas oblíquas, círculos, curvas etc., que dão forma compositiva a esses grafemas ou letras. Coube aos tipógrafos nomear tais elementos compositivos das letras através de metáforas antropomórficas, tais como a barriga, braço, orelha, ombro etc. para letras de forma ou bastão e laços, taças, argolas, dentre outros, para letras cursivas.

Além disso, eles acrescentam que por meio do aprendizado da metalinguagem criada para designar os elementos compositivos das letras, os alunos em processo de alfabetização tornam-se familiarizados com os sinais gráficos através da utilização de uma linguagem familiar (barriga, olho, laço, argola etc.).

Ademais, considera-se que os designers acompanham os desenvolvimentos tecnológicos na contemporaneidade e tentam incorporar novas técnicas e ferramentas no cotidiano da profissão, mantendo-se atualizados com o que tem sido desenvolvido ao redor do mundo. Neste sentido, ao juntar-se os conhecimentos tipográficos com a tecnologia e, trabalhando-se por meio da interdisciplinaridade no ambiente escolar, é possível criar soluções metodológicas no que diz respeito ao ensino da escrita manual cursiva, aproximando a mesma do contexto dos nativos digitais.

\section{CONSIDERAÇÕES FINAIS}

O uso da escrita manual cursiva deve ser incentivado no dia-a-dia dos nativos digitais, pois sabe-se que o estímulo à produção de uma letra própria em crianças em alfabetização é importante para a criação de um sistema de leitura no cérebro em desenvolvimento, contribuindo para a identificação das letras quando lidas pelos escolares, além do aprimoramento dos conhecimentos ortográficos.

Portanto, a partir da natureza interdisciplinar do Design, percebe-se a possibilidade de se realizar um trabalho em conjunto com os professores a fim de buscar-se por soluções que poderão auxiliá-los no processo de ensino da escrita manual cursiva dos nativos digitais em alfabetização para que, ao longo dos anos letivos, consiga-se manter o interesse dos alunos em valorizar uma escrita pessoal e manual.

Por intermédio do princípio interdisciplinar de Educação através do Design (EdaDe), uma forma inovadora de trabalho com os alunos são atividades de design, cuja finalidade não é apenas estimular a prática e o executar, mas antes, envolve a compreensão do que será feito e, especificamente, o aprendizado da escrita manual cursiva.

Sendo assim, por meio dessas atividades, seria possível, além de estimular o desenho e a construção das letras cursivas, o pensamento crítico, o senso estético e outras características, aliados aos conhecimentos tipográficos e metodológicos práticos dos designers e demais disciplinas que poderiam se envolver no processo. Caberia, portanto, aos professores e designers estudar juntos formas e técnicas adequadas ao contexto dos nativos digitais, para que haja o estímulo e o despertamento do interesse em se escrever à mão.

Ademais, o ato de se escrever à mão está presente em nossa sociedade há mais de seis mil anos. Julga-se que a escrita manual cursiva é parte constituinte da expressão pessoal de cada indivíduo, adquirida ao longo do processo de alfabetização 
e estilizada conforme a criatividade e preferência de quem a utiliza. É única e capaz de carregar consigo a pessoalidade, o significado e a identidade que não podem ser alcançados por meio das letras digitais.

\section{REFERÊNCIAS}

BAPTISTA, Adriana; VIANA, Fernanda Leopoldina; BARBEIRO, Luís Filipe. O ensino da escrita: dimensões gráfica e ortográfica. Biblioteca Nacional de Portugal, 2011.

Disponível em:

<http://repositorium.sdum.uminho.pt/bitstream/1822/31557/1/ensino_escrita\%20di mens\%C3\%B5es\%20gr\%C3\%A1fica\%20e\%20ortogr\%C3\%A1fica.pdf>. Acesso em: 6 de ago. 2015.

BONATTO, Andréia; BARROS, Caroline Ramos; GEMELI, Rafael Agnolleto; LOPES, Tatiana Bica; FRISON, Marli Dallagnol. Interdisciplinaridade no ambiente escolar. In: IX ANPEDSUL: SEMINÁRIO DE PESQUISA EM EDUCAÇÃO DA REGIÃO SUL. Caxias do Sul, 2012. Disponível em:

<http://www.ucs.br/etc/conferencias/index.php/anpedsul/9anpedsul/paper/viewFile/ 2414/501>. Acesso em: 8 de out. 2015.

BORDENOUSKY FILHO, Renato; FONTOURA, Antônio Martiniano; OBERG, Lígia; URSI, Erika Simioni. Pró EdaDe - programa de educação através do Design. In: V EDUCERE: Congresso Nacional de Educação. Curitiba, 2005. Disponível em:

<http://www.pucpr.br/eventos/educere/educere2005/anaisEvento/documentos/com /TCCI093.pdf>. Acesso em 6 de ago. 2015.

BROWN, Tim. Design Thinking: uma metodologia poderosa para decretar o fim das velhas ideias. 11.ed. Rio de Janeiro: Elsevier, 2010.

CARVALHO, Ricardo. Estados americanos abolem escrita à mão nas escolas. Carta Capital, publicado em 25 de julho de 2011, às 10h10. Disponível em:

<http://www.cartacapital.com.br/sociedade/novos-tempo>. Acesso em: 30 de out. 2015.

COUTINHO, Solange Galvão; LOPES, Maria Teresa. Design para a educação: uma possível contribuição para o ensino fundamental brasileiro. In: BRAGA, Marcos da Costa (org.). O papel social do Design Gráfico. São Paulo: Editora Senac São Paulo, 2011. p. $137-162$.

FANTIN, Monica; RIVOLTELLA, Pier Cesare. Crianças na Era Digital: desafios da comunicação e da educação. Revista de Estudos Universitária, Sorocaba, SP,v. 36, n. 1, 7, 2010, p. 89-104. Disponível em:

<http://www.nica.ufsc.br/index.php/publicacoes/fantin/doc_download/4-criancas-naera-digital-desafios-da-comunicacao-e-da-educacao >. Acesso em: 7 de out. 2015.

FARIAS, Priscila Lena. Aprendendo com as ruas: a tipografia e o vernacular. In: BRAGA, Marcos da Costa (org.). O papel social do Design Gráfico. São Paulo: Editora Senac São Paulo, 2011. p. 137 - 162. 
FOUNTOURA, Antônio Martiniano. EdaDe: A educação de crianças e jovens através do Design. Tese (Doutorado em Engenharia de Produção) - Universidade Federal de Santa Catarina, Florianópolis, 2002. Disponível em:

<https://repositorio.ufsc.br/handle/123456789/82554?show=full>. Acesso em: 24 de fev. 2015.

FONTOURA, Antônio Martiniano. A interdisciplinaridade e o ensino do design.

Projética Revista Científica de Design. Universidade Estadual de Londrina. v.2, n.2, dezembro, 2011. Disponível em:

<http://www.uel.br/revistas/uel/index.php/projetica/article/view/8855>. Acesso em

24 de mar. 2016.

HENRIQUES, Fernanda; MARGADONA, Laís Akemi; GADOTTI, Marcela. Analógicos X Digitais: uma batalha sem vencedores. In: PEREIRA, Ana Beatriz et al. Ensaios de Design: práticas interdisciplinares. Bauru, SP: Canal 6, 2014. p. $206-222$. Disponível em: <http://canal6.com.br/ensaios/>. Acesso em 30 de out. 2015.

KERSEY, Alyssa; JAMES, Karin H. Brain activation patterns resulting from learning letter forms through active self-production and passive observation in young children.

Lausanne, Switzerland: Frontiers in Psychology: Cognitive Science, v 4, article 547, p. 1 - 15, 2013. Disponível em:

<http://www.ncbi.nlm.nih.gov/pmc/articles/PMC3780305/pdf/fpsyg-04-00567.pdf> acesso em 23 de set. 2015.

LEMOS, Silvana. Nativos digitais $\mathbf{x}$ aprendizagens: um desafio para a escola. Senac, $\mathbf{v}$. 35, n.3. Rio de Janeiro, 2009.

OLIVEIRA, Alexandre Santos de; TEIXEIRA, Narle Siva; MACIEL, Francimar Rogrigues. Design, educação, criatividade e as possibilidades de mediação dos processos de ensino e aprendizagem. Revista Design em Foco, v.3. n.2. Salvador: EDUNEB, 7, 12, 2006. p. 117-128. Disponível em:

<http://www.redalyc.org/pdf/661/66111515009.pdf>. Acesso em: 12 de out. 2015.

SOARES, Magda. Novas práticas de leitura e escrita: letramento na cibercultura. Campinas, São Paulo: Educ. Soc., vol. 23, n. 81, p. 143-160, 2002. Disponível em: <http://www.cedes.unicamp.br>. Acesso em: 7 de out. 2015.

. Língua escrita, sociedade e cultura: Relações, dimensões e perspectivas. In:

XVII Reunião Anual da ANPEd, Caxambu, 1995. Disponível em:

<http://anped.org.br/rbe/rbedigital/rbde0/rbde0_03_magda_becker_soares.pdf >. Acesso em: 1 de out. 2015.

VERAS, Marcelo (org.). Inovação e métodos de ensino para nativos digitais. São Paulo: Atlas, 2011. 